\title{
AN INTELLIGENT AGENT FOR MONITORING AND DETECTING COUNTERFEIT PRODUCTS
}

\author{
ARU OKEREKE EZE ${ }^{1}$, AMEGASHIE RICHARD J. ${ }^{2}$, and UGOJI FRANK-GODRIC C. ${ }^{3}$ \\ ${ }^{1-3}$ Department of Computer Engineering \\ College Of Engineering, Michael Okpara University of Agriculture, Umudike \\ Umuahia, Abia State \\ Nigeria
}

\begin{abstract}
In the world global market today, there is an increasing threat that product are not what consumer's and end users think they are, industries, manufacturing Companies as well as commercial Companies which run on a web based platformface the challenges of faking their products, therefore causing downstream in sales and quality of products in the market. The aim of this research is to design and develop an intelligent agent for monitoring and detecting counterfeit products. In this project, Barcode technology was used to develop a web based intelligent agent for monitoring and detecting counterfeit products, Qualitative and quantitative research methodology was adopted in this research in which questionnaire was used to determine the impact of counterfeit products on consumers and business and also to ascertain the ability of the consumers to identify counterfeit products. Based on the findings from this research, it is shown that the application of this system in the global market can help minimize and if possible eradicate counterfeit products from the global markets.
\end{abstract}

Key words: Barcode, Products, Counterfeit, Consumers, Markets, Technology.

\subsection{INTRODUCTION}

In the world global market today, there is an increasing threat that products are not what consumers and end users think they are. Research has shown that the rapid growth of trade in counterfeit products is engineered by a number of factors from limited supply of genuine products and inability to identify original products. Counterfeiting products is one of the major issues, which most product manufacturers and consumers have to confront. The most serious cases of product being counterfeited is when substandard products are being consumed or used unknowingly, by deceived consumers and end users. It is usually dangerous when it targets security applicable products such as cars or airplanes spare parts, food and beverages and pharmaceuticals. According to Grossman and Shapiro (1988), not all counterfeited products are manufactured to influence the consumer that they are buying the originals product and this is when the products selling is divided into two different classes, namely; deceptive and non-deceptive counterfeiting ${ }^{[1]}$. According to Bloch, Bush and Campbell (1993), the two different counterfeiting sources are deceptive and non-deceptive. Non deceptive is any position where the consumer knows the true origin/identity of the product and knows it is a forged copy of the original product, whereas the deceptive counterfeiting is any condition where the consumer does not know the true identity of the product manufactured and or that it is a copied of the original product which means that they don't know that is a counterfeit product ${ }^{[2]}$. These products need to conform to adequate quality and safety standards, but counterfeit products do not provide such guarantees. The high rate of increase in counterfeit products in the market today is as a result of the recent total removal of import restriction and control, digital technology, globalization and trade liberalization policies. It is this escalating condition that were called to actions for venturing into this research work so as to be able to develop a system that will be used to detect a counterfeit product from a genuine product.

Python flask barcoding technology is a programming language that involves designing a barcode. Barcode consist of vertical bars separated by white gaps that are aligned in parallel pattern. There are wide and narrow sizes which are arranged 
according to a predetermined code to indicate a corresponding number and symbol. An optical scanner that consist of a laser is used to read and decode the information and detect the originality of a product to know if the product is genuine or counterfeit from the barcode. However, despite being in their physical design every barcode represents a unique code in the item list. Traditionally, a barcode reader is an electronic device that can read an output printed barcode to a computer. The barcode scanner is used by retailers to keep track of inventory, and speed up data entry due to heavy commercial and industrial sector usage. Barcode scanning application has been producer-centric, focusing on improving the efficiency, accuracy and productivity of supply management. In addition, the system is consumer-centric. Barcode are much cheaper than employing another technology such as Radio Frequency Identification (RFID). Radio Frequency Identification requires purchase of tags, whereas, barcode technology requires just inking costs. From a cost point of view, it makes sense to use barcode technology to detect whether a product is counterfeit or genuine. Counterfeit products are creating an enormous drain on the global economy, which is generating an underground trade that is depriving Governments from their revenue.

\subsection{REVIEW OF RELATED WORKS}

Zhon and Hui (2003) highlight the possibility that counterfeit will decline the symbolic value of authentic luxury brand and consequently dilute the brand equity. As counterfeits are cheaper options, there might not be a noticeable different in perceived quality ${ }^{[3]}$.

A study of the work of Tom et al (1998) reveals that consumer is more inclined to purchase products with a popular component attached. Consumers are willing to pay for the visual attributes and functions without paying for the associate quality ${ }^{[4]}$.

According to Cordell et al (1996), he reinforce the concept that only well-known brands are counterfeited ${ }^{[5]}$.

According to Cordell et al (1996) price has been found to be one of the major motivators of counterfeit ${ }^{[5]}$.

According to Cordell et al., (1996) and Chaddle (2007) the mind of consumer, price is reflective of attitude respond to the value of counterfeits products, with intent, counterfeits capitalize on the fact that counterfeit are sole at a lower price hence creating a price advantage over genuine products ${ }^{[5]}$.

In the work of Centre et al (2006), Yoo and Lee (2012) on the same note, consumers is forced to purchase products, but are unwilling to pay the hefty price tag attached to it $^{[6]}$.

Bloch et al (1993), Prendergest et al (2002) and Tang et al (2014)stipulated that because of the lower prices, there is lower expectation of quality as long as the basic functional requirement are met or the visibility and symbolic value is achieved, consumer will be satisfied ${ }^{[7]}$.

A study of the Schuchert (2006) reveals that there are consumers who only want to acquire the Look of the original brand but do not seek further satisfaction from owning the original ${ }^{[8]}$.

In the work of Wilcox et al (2009), there are grade system attacked to the counterfeit to enable consumer to decide the level of counterfeit ${ }^{[9]}$.

\subsection{THE IMPACT OF COUNTERFIET TRADE ON ECONOMY}

Organization for Economic Co-operation and Development OECD, Staake and Fleisch (2008), share the opinion that the impact of counterfeiting is significantly to the originator ${ }^{[10]}$. The effect of counterfeiting can be extremely unfit for the "creator" of the products. The counterfeit products are at times very appealing, usually of low quality, and of low pricing than the genuine ones. Trading counterfeit products usually favorable and is a growing venture and proof reveals that there is an obvious connection between counterfeits trade and money laundering and drug trafficking. Initially manufacturer of very high priced and very reputable products like jewels, and electronics are affected by the growing technology (Staake \& Fleisch 2008).

These losses not only affect the producers of genuine items, but they also include social costs. It is estimated that trade in counterfeit products is now worth more than five per cent of world trade.

At first momentary look, it is evident that consumers buy counterfeit goods based on their low and affordable prices, this would actually suggest that counterfeits are primarily attractive to low income earner but in reality even the high income 
earners also buy counterfeit products. According to the report of Anti -Counterfeit Agency joint with Kenya Association of Manufacturers and Kenya Private Sector Alliance (2011), the following are the impacts of counterfeit trade to the economy:

- Counterfeiters habitually pay taxes or the appropriate duties and rates.

- Counterfeiters sustain limited production costs, thus they can outlay to sell their products inexpensive and thereby destabilize genuine producers. This bankrupt business of deserved profits.

- Counterfeit product poses great risks to public health and safety.

- Counterfeit trade may lead to assumed trade relationships among Intellectual Property owners and counterfeiters.

\subsection{RESEARCH METHODOLOGY}

Qualitative and quantitative research methodology was adopted in this research in which questionnaire was used to determine the impact of counterfeit products on consumers and business and also to ascertain the ability of the consumers to identify counterfeit product. Data was collected from the targeted population to this effect and also analyzed.

\subsection{ANTICIPATION OF THE SYSTEM}

Design and development of an intelligent agent for detecting counterfeit products is very vital to the industries and manufacturing companies, as well as commercial companies which runs a web-based platform. In this platform, the admin creates account for each product and the user has a privilege to generate barcode for each product in the factory. This system has a barcode verification panel, the user verifies if a product is a counterfeit product or genuine product. To achieve that, the information about a product is encrypted into the barcode and when scanned displays on the screen for the user to know if the product is genuine or not.

\subsection{FLOW DIAGRAM OF THE NEW SYSTEM}

Flow diagram of new system is shown in figure 3.1 .

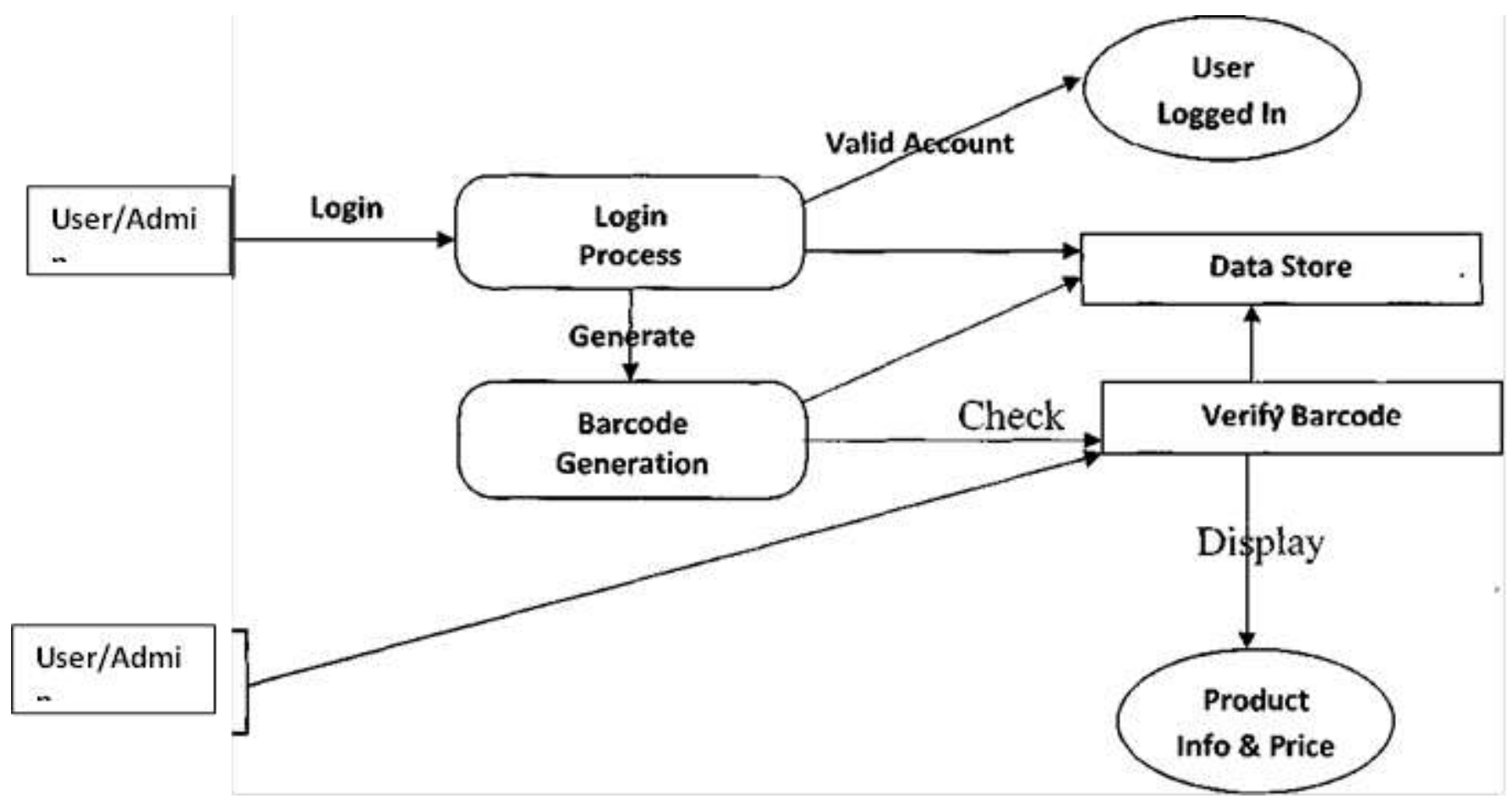

Figure no. 3.1. Flow diagram of New system

\subsection{ANALYSIS}


International Journal of Advances in Scientific Research and Engineering (ijasre), Vol 5 (7), July-2019

The average analysis of the respondent responses on the impact of counterfeit products on business and economy is shown in the table and depicted by the chart below

Table 4.0.1: Views of respondents on the impact of counterfeit products on business and economy

\begin{tabular}{|c|c|c|}
\hline Views of respondents & Frequency & \%Percentage \\
\hline $\begin{array}{c}\text { Negatively affects } \\
\text { business/economy/social life }\end{array}$ & 102 & 72.9 \\
\hline Creates profit & 28 & 20 \\
\hline Creates employment & 10 & 7.1 \\
\hline Total & 140 & 100 \\
\hline
\end{tabular}

From table 4.0 .1 , it is shown that $72.9 \%$ of the respondents indicated that counterfeit products has negatively affected business/economy, $20 \%$ of the respondent indicated that it has increased profit in business whereas only $7.1 \%$ reviled that it created employment opportunities.

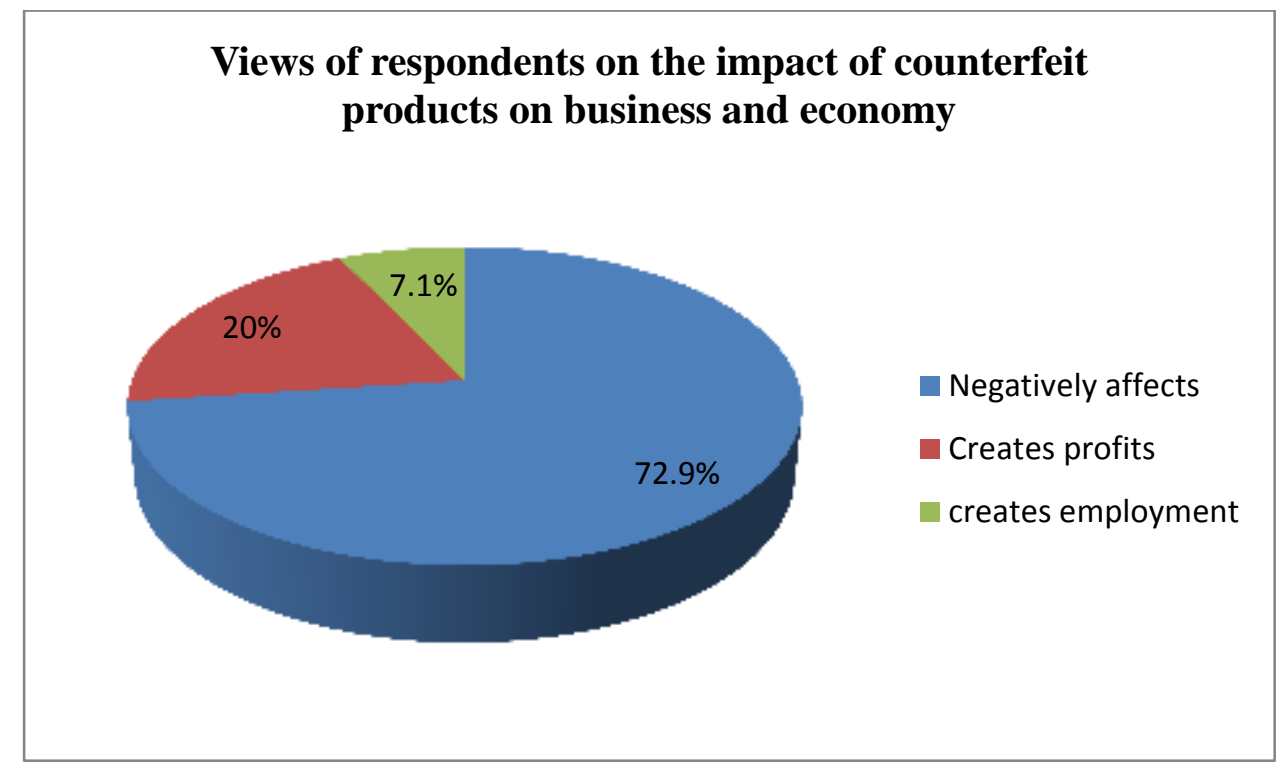

- Fig 4.0.1: Views of respondents on the impact of counterfeit products on business and economy

\subsection{DESIGN VIEW OF THE SYSTEM}

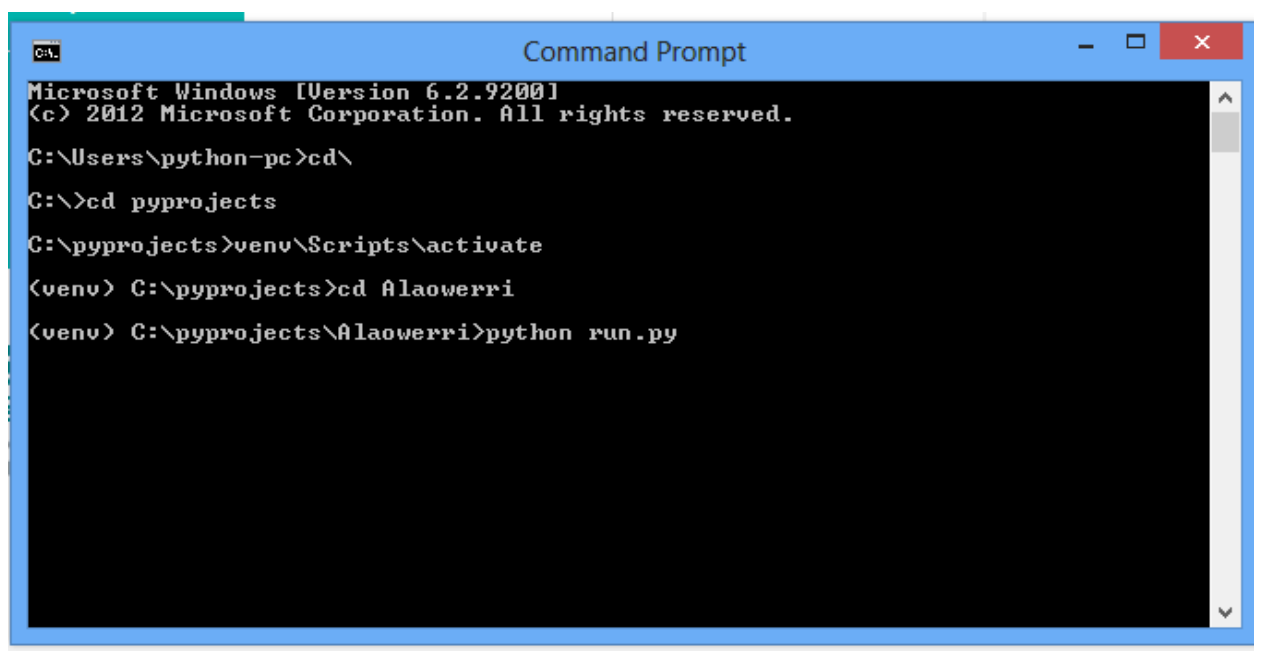

Fig. 4.1.1: Command Prompt interface for Starting of the python server 
International Journal of Advances in Scientific Research and Engineering (ijasre), Vol 5 (7), July-2019

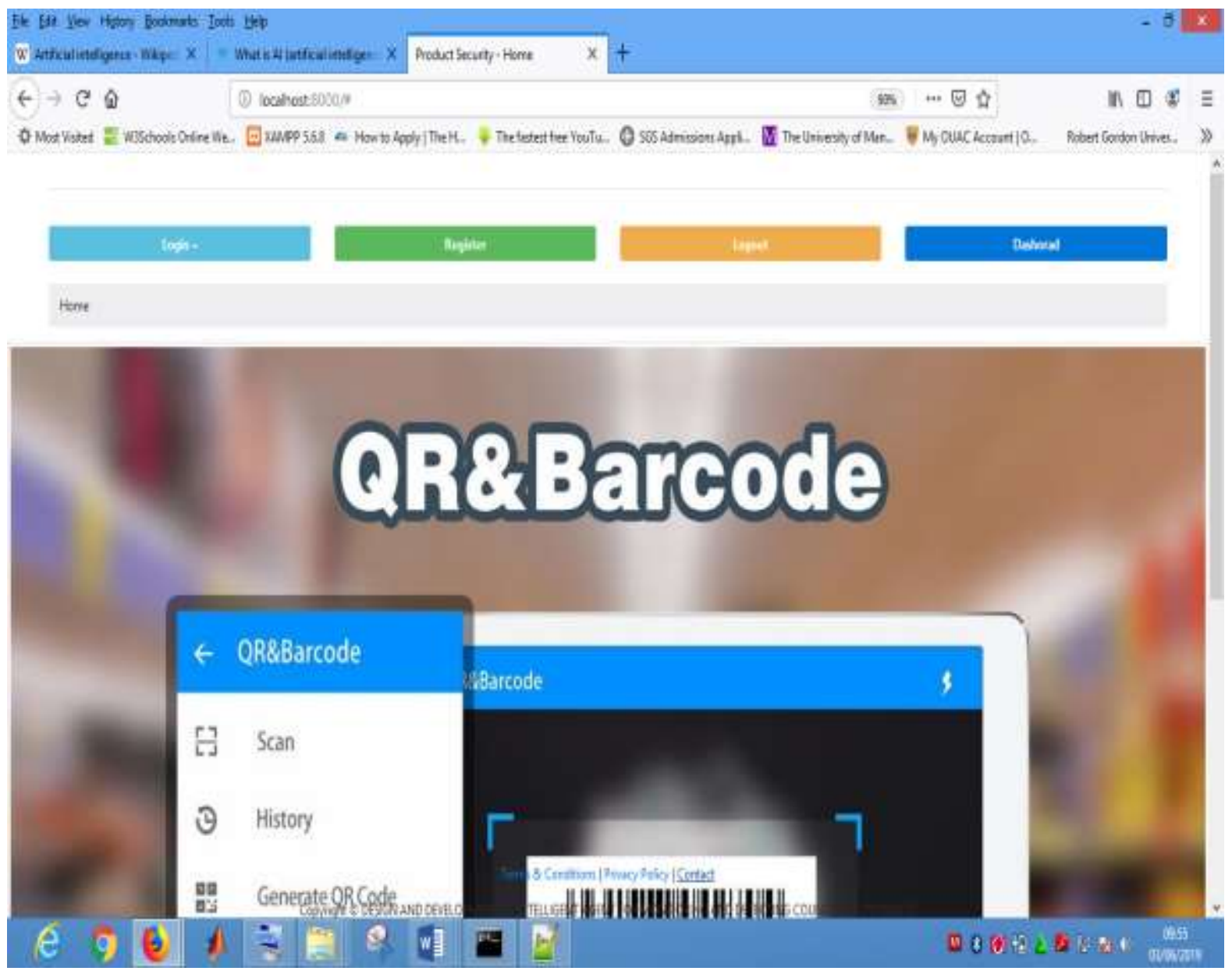

Fig. 4.1.2: The Home Page.

This is the main page of the system that has the link to all the different pages of the platform

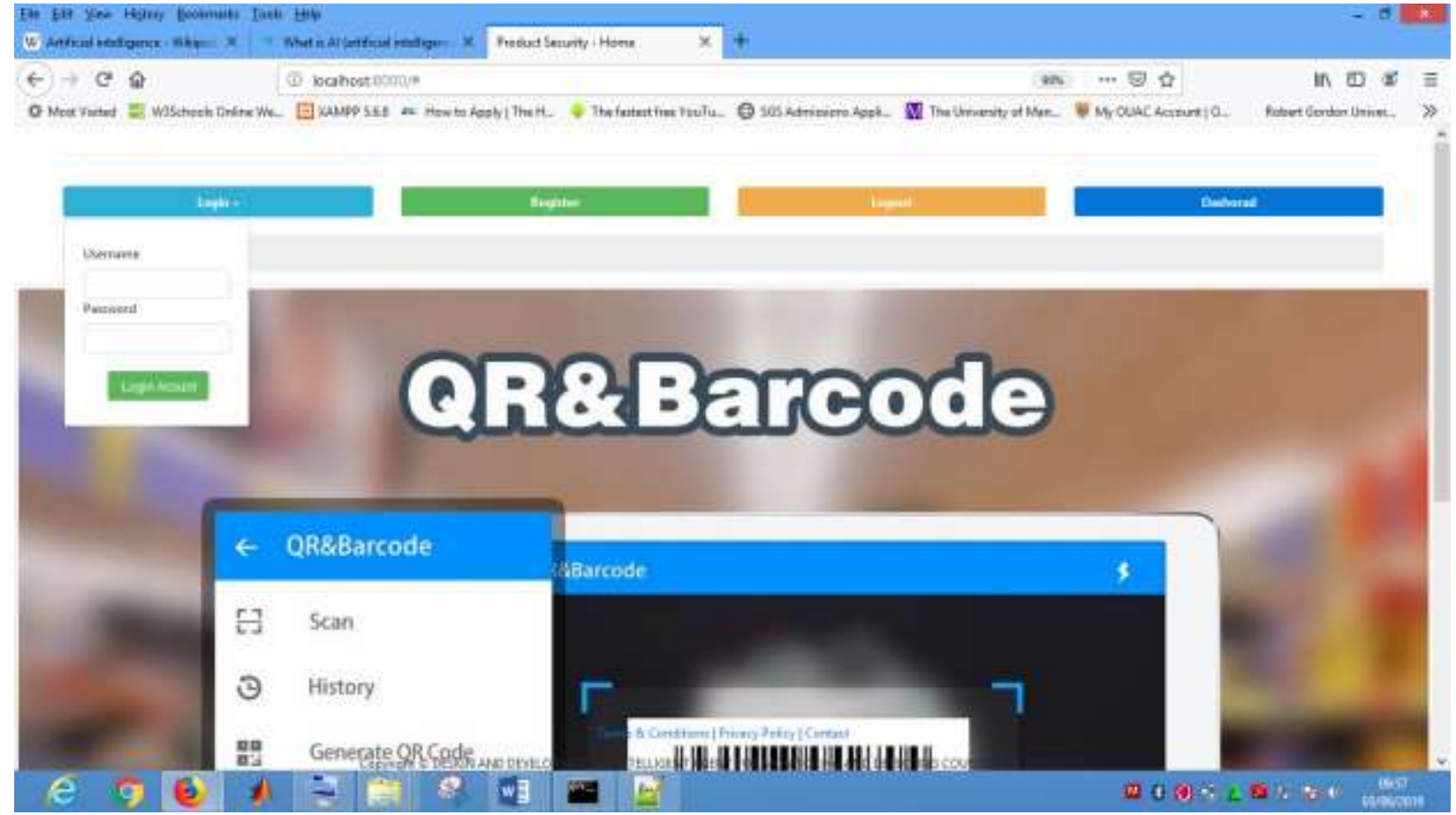

Fig. 4.1.3: The Login Page.

This is one of the modules of the system that enables a user to Log into the platform. It is an authentication panel that makes sure that only the authorized users have access to the platform. 
International Journal of Advances in Scientific Research and Engineering (ijasre), Vol 5 (7), July-2019

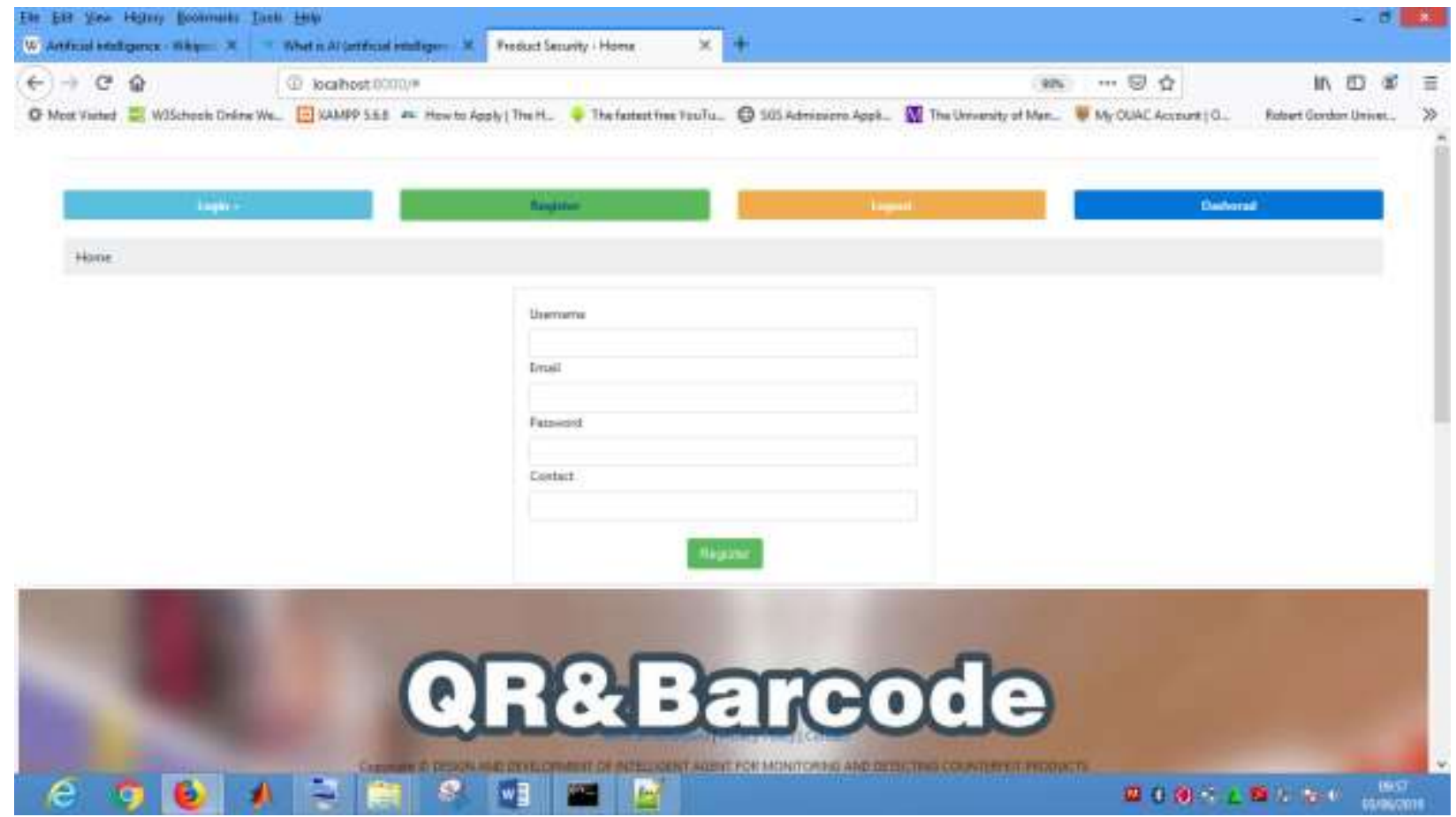

Fig. 4.1.4: The registration Page.

This is one of the modules of the system that enables a user to register his or her name into the database

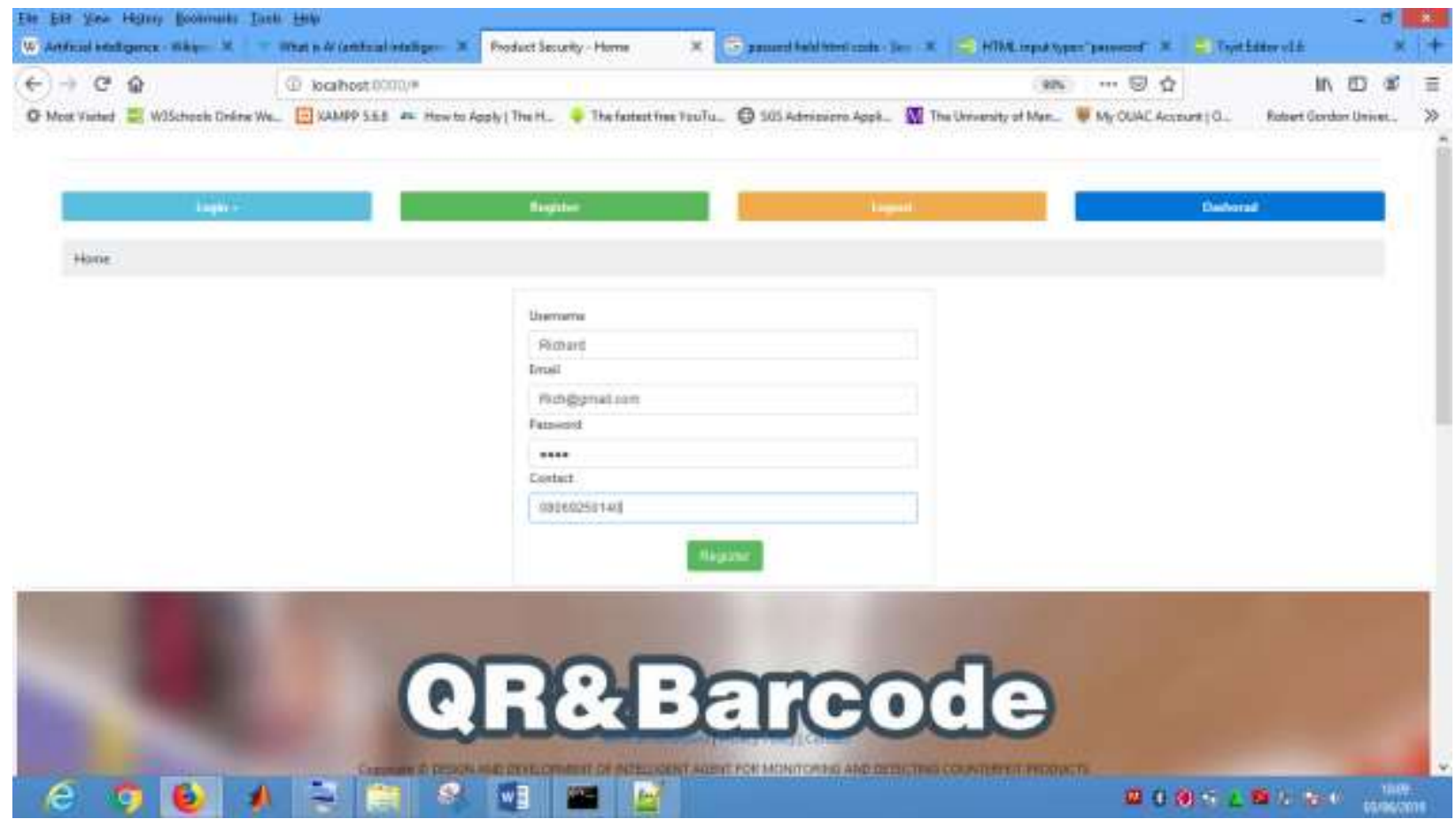

Fig. 4.1.5: The registration Page.

This is one of the modules of the system that enables a user to register his or her name into the database. Here, registration is being made to show the system works. 
International Journal of Advances in Scientific Research and Engineering (ijasre), Vol 5 (7), July-2019

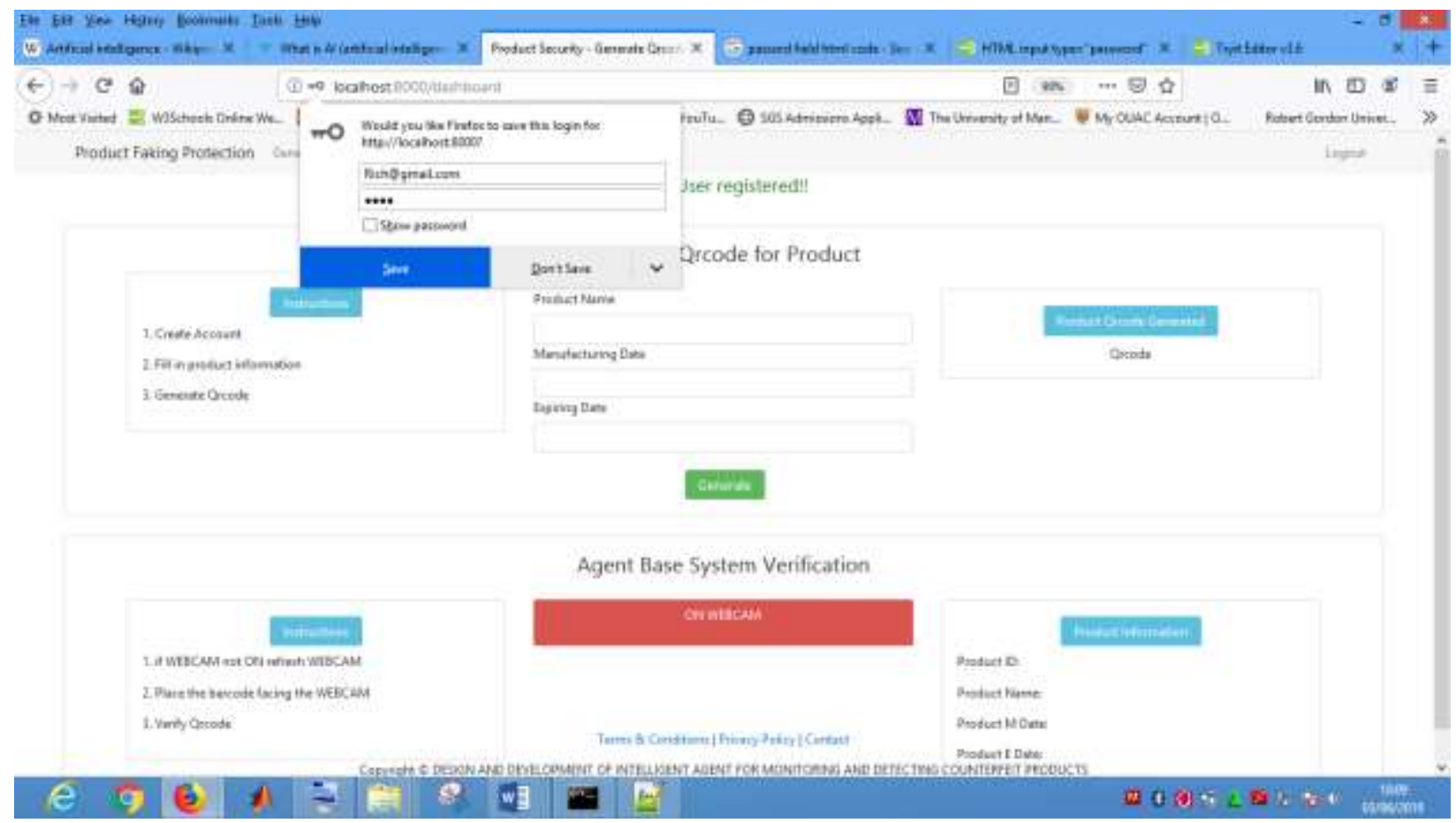

Fig. 4.1.6: Product registration Page.

This is one of the modules of the system that enables one to register products into the database.

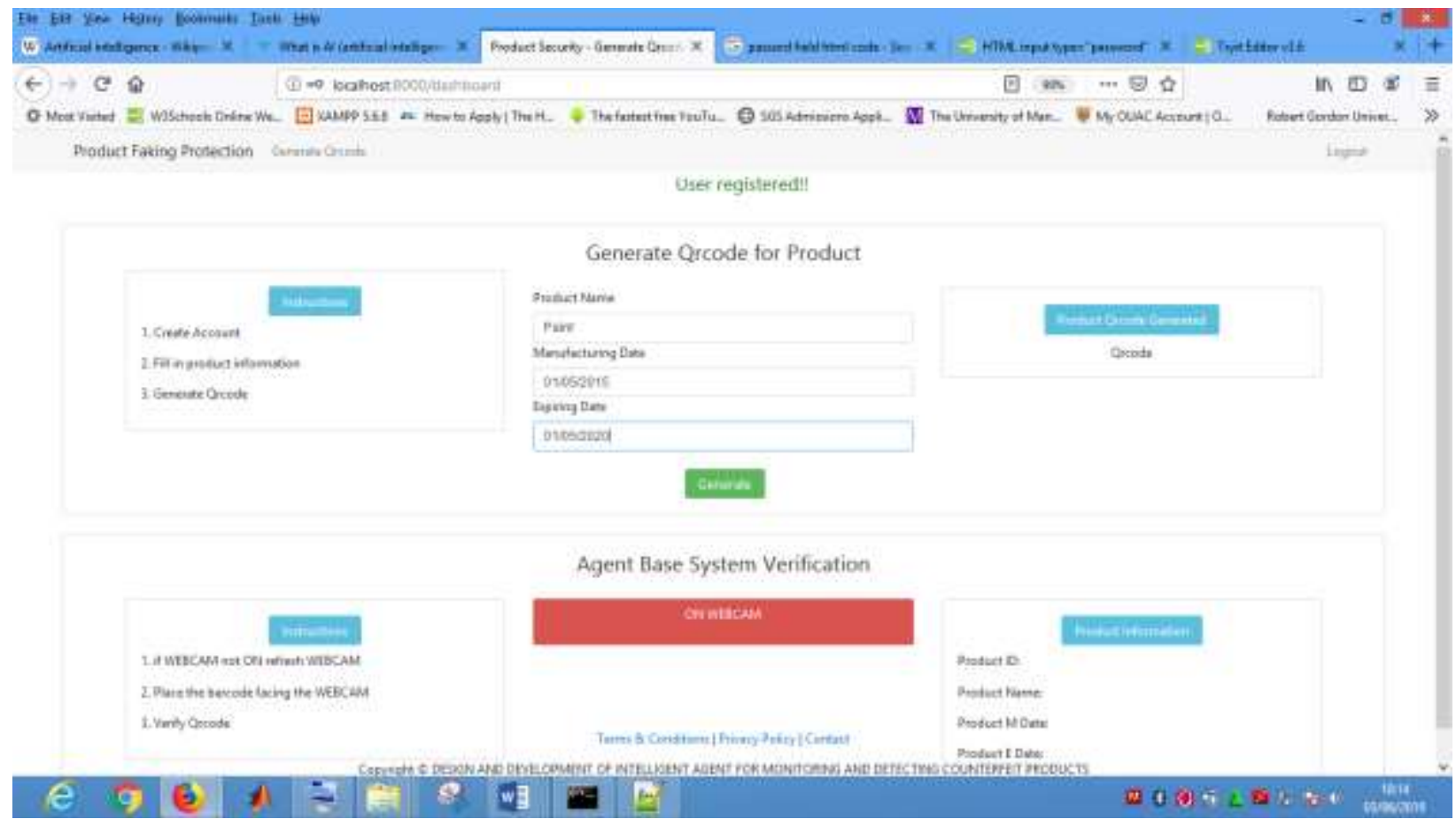

Fig. 4.1.7: Product registration Page.

Here, products are being saved into the database and Qrcode is generated too. 
International Journal of Advances in Scientific Research and Engineering (ijasre), Vol 5 (7), July-2019

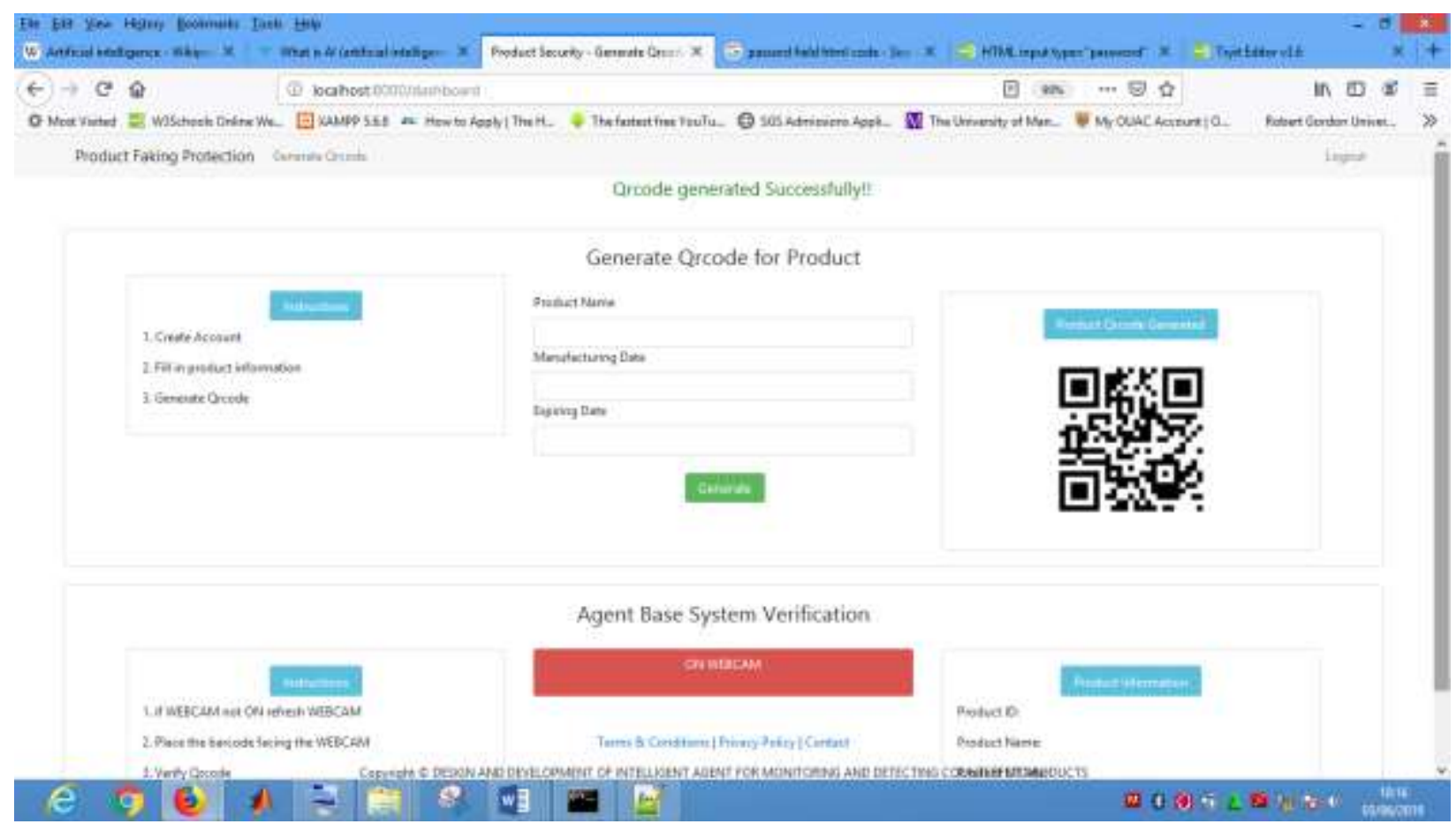

Fig.4.1.8: Product registration Page

Here, qrcode is being generated.

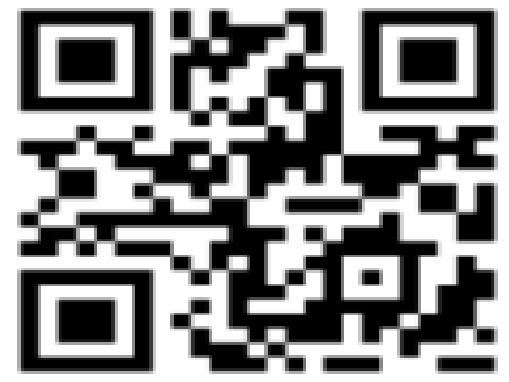

4.1.9: This is a generated qrcode for a specific product.

Here, once a button is clicked, it automatically prompts the webcam which will automatically scan the qrcode and send the information the already saved database of genuine products and, displaying the product information. 


\section{Intelligent Agent Panel For Monitoring and Detecting Counterfeit Products}

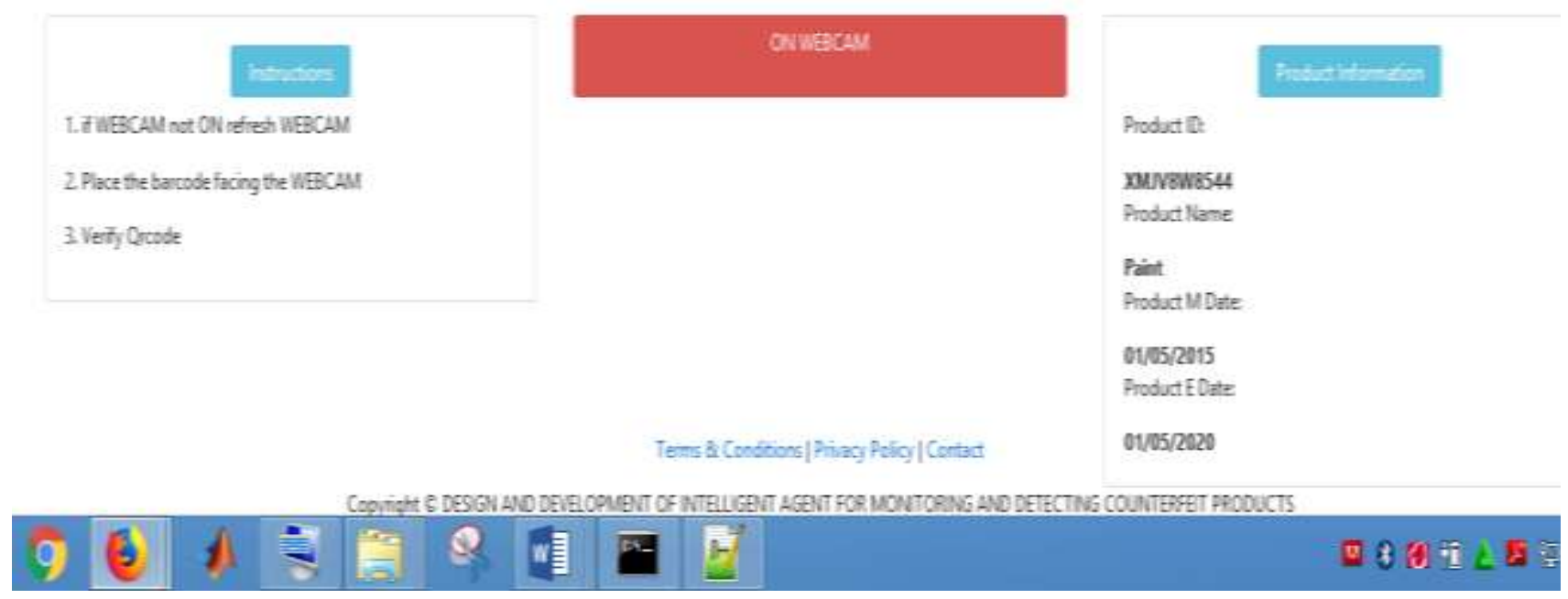

Fig. 4.1.10: Counterfeit detection Panel.

\subsection{CONCLUSION}

From the study, it is very clear that the problem of counterfeit products continue increasing every day, business owners are continuously trading counterfeit product not minding the danger it may bring to them and the consumers. It is also very clear that the current stale of the country's economy have also contributed to the growth of and success of trading counterfeit products. Based on the findings from this research, it is shown that the application of this system in the global market can help minimize and if possible eradicate counterfeit products from the global market.

Finally, the trading of Counterfeit products is a vice and should be eradicated by the law enforcement agencies.

\section{REFERENCES}

1. Grossman and Shapiro, (1988), “Foreign counterfeiting of status goods”, Quarterly Journal of Econnomics, volume 103, issue 1, February 1988, pages 79-100

2. Bloch, P. et al, (1993)," Consumer "Accomplishes" in product counterfeiting", Journal of consumer marketing, Vol. 10, Issue 4, pp. $24-34$

3. Zhou and Hui, (2003), "symbolic value of foreign product in the people's republic of china", Journal of international marketing, summer 2003, vol.11, no.2, pp36-58

4.Tom, G et al, (1998), "Consumer demand for counterfeit goods" psychology and marketing, Vol.15, issue 5, pp. 405 -421.

5. Cordell, V et al (1996) "counterfeit purchase intenicn: Role of Lawfulness Attitude and product trails as determinant"' Journal of Business Research Vol. 35, Issue 1. pp. 41 -53.

6. Yoo, B. et al., (2000), " An examination of selected marketing mix Elements and Brand Equity", Journal of the Academy of marketing science, Vol 128, pp. 195-211.

7. Bloch, P. et al, (1993)," Consumer "Accomplishes" in product counterfeiting", Journal of consumer marketing, Vol. 10, Issue 4, pp. $24-34$.

8. Eisend, M and Schuchert-Guler,P., (2006), “Explaining counterfeit purchases: A Review and Preview”, Academy of Marketing Science Review, 12, 1-22

9. Wilcox, K., (2009)," why do consumers buy counterfeit Luxury brand? Journal of marketing research, Vol. 46, Issue 2, pp. 247 259.

10. Staake, \& Fleisch, (2008) countering counterfeit Trade: illicit market insight, Zurich Switzerland, ATH Zurich, department of management publishers. 